\title{
TdT Negativity and ETP Phenotype in Young Patients with Acute T- Lymphoid Leukemia: A Case Report
}

\author{
Cetin $D^{1 *}$, Midık MM${ }^{1}$, Karadag FK ${ }^{2}$, Ozsan $\mathbf{N}^{3}$, \\ Parıltay $\mathrm{E}^{4}$, Akın $\mathrm{H}^{4}$ and Saydam $\mathrm{G}^{2}$ \\ ${ }^{1}$ Department of Internal Medicine, Ege University School \\ of Medicine, Turkey \\ ${ }^{2}$ Department of Hematology, Ege University School of \\ Medicine, Turkey \\ ${ }^{3}$ Department of Pathology, Ege University School of \\ Medicine, Turkey \\ ${ }^{4}$ Department of Medical Genetics, Ege University School \\ of Medicine, Turkey \\ *Corresponding author: Denis Cetin, Department of \\ Internal Medicine, Ege University School of Medicine, \\ Bornova, Izmir, Turkey
}

Received: February 26, 2021; Accepted: March 29, 2021; Published: April 05, 2021

\section{Introduction}

Acute Lymphoblastic Leukemia (ALL) is a hematopoietic malignancy, which is caused by uncontrolled proliferation of immature B/T lymphoid cells. In the United States of America (USA), the incidence of ALL at all ages is 1.38/100,000 people per year, with an estimated 5930 new cases and 1500 deaths due to ALL [1,2]. ALL is more common in childhood than in adults. It constitutes $75-80 \%$ of childhood acute leukemias [3]. The average age of diagnosis is 15 years old and $55.4 \%$ of the patients are under 20 years old [4,5].

According to the immunophenotype classification, ALL originates from B cells (B-ALL) and T cells (T-ALL); $85 \%$ and $15 \%$ respectively [6,7]. Among ALL, T-ALL is detected in adults at a higher rate compared to childhood, but this rate decreases as the age progresses [8]. The World Health Organization (WHO) defines T-ALL as Terminal Deoxynucleotidyl Transferase (TdT) as well as lymphoblasts where the markers CD1a, CD2, CD3, CD4, CD5, CD7 and $\mathrm{CD} 8$ are positive. Cytoplasmic $\mathrm{CD} 3(\mathrm{cCD} 3)$ and $\mathrm{CD} 7$ are also often positive. T-ALL can be divided into pro-T, pre-T, cortical $\mathrm{T}$ and medullary $\mathrm{T}$ according to the stages of intra-thymic differentiation $[9,10]$. In addition, early $\mathrm{T}$ cell precursor (ETP) immunophenotype has been identified according to surface markers (lack of CD1a and CD8 expression, negative or weak CD5 expression, and one or more myeloid or stem cell marker expression) [11]. Although it was reported that $\mathrm{TdT}$ is negative in $5-12 \%$ of cases, $\mathrm{TdT}$ is usually positive at T-ALL [12-16].

TdT is an intranuclear DNA polymerase that catalyzes the addition of deoxynucleotides to oligonucleotides. TdT is highly expressed in lymphoid precursors where it plays a pivotal role in T-cell receptor and immunoglobulin heavy chain gene rearrangement. Indeed, almost all cortical thymocytes and a small subset of bone marrow $\mathrm{B}$-cells express $\mathrm{TdT}$ in their nuclei. TdT is an important marker in distinguishing ALL from reactive conditions or mature lymphoid neoplasms [17].
Herein, we reported the diagnosis process and the management of a patient who has TdT negative T-ALL with ETP immunophenotype.

\section{Case Presentation}

A 20-year-old female patient with no known additional diseases applied to our health facility due to painless swelling behind the right ear. There was no weight loss, fever, or night sweats in the system questionnaire. On her physical examination, bilateral posterior auricular, submandibular, jugular, supraclavicular, left axillary, bilateral inguinal lymphadenopathy and hepatosplenomegaly were detected. In laboratory examination, hemoglobin $12 \mathrm{~g} / \mathrm{L}$, leukocyte count $8.92 \times 10^{3} / \mu \mathrm{L}$, neutrophil count $1.11 \times 10^{3} / \mu \mathrm{L}$, lymphocyte count $6.81 \times 10^{3} / \mu \mathrm{L}$, platelet count $137 \times 10^{3} / \mu \mathrm{L}$, erythrocyte sedimentation rate $44 \mathrm{~mm} /$ hour, C-Reactive Protein (CRP) $20.26 \mathrm{mg} / \mathrm{L}(0-5$ $\mathrm{mg} / \mathrm{L}$ ), Lactate Dehydrogenase (LDH) 513 U/L (135-225). Her renal function, liver function, and electrolytes were normal on biochemical laboratory evaluation.

On peripheral blood smear $40 \%$ blasts were seen and bone marrow aspiration and biopsy were performed. Bone marrow biopsy showed $90 \%$ narrow basophilic cytoplasm blast population. Immuno-histochemical examinations revealed extensive and strong positive with $\mathrm{CD} 3$ and $\mathrm{CD} 10$, mostly positive with $\mathrm{CD} 34$ and negative staining with TdT. It is shown in Figure 1.

In bone marrow aspiration flow cytometric examination CD1a (-), cTDT (-), CD4 (-), CD8 (-), CD19 (-), MPO (-), CD2 (+), CD3 $(+), \mathrm{CD} 5(+), \mathrm{CD} 7(+), \mathrm{CD} 10(+), \mathrm{HLA}-\mathrm{DR}(+), \mathrm{CD} 13(+), \mathrm{CD} 33(+)$ were detected. The patient was diagnosed as TdT negative T-ALL with ETP immunophenotype.

In the cytological examination of Cerebrospinal Fluid (CSF) sampling and in radiodiagnostic intervention there were no findings in favor of primary disease involvement. In karyotype analysis, isolated del (16) (q22) was detected. It is shown in Figure 2.

As an induction regimen, Augmented Hyper-CVAD treatment 


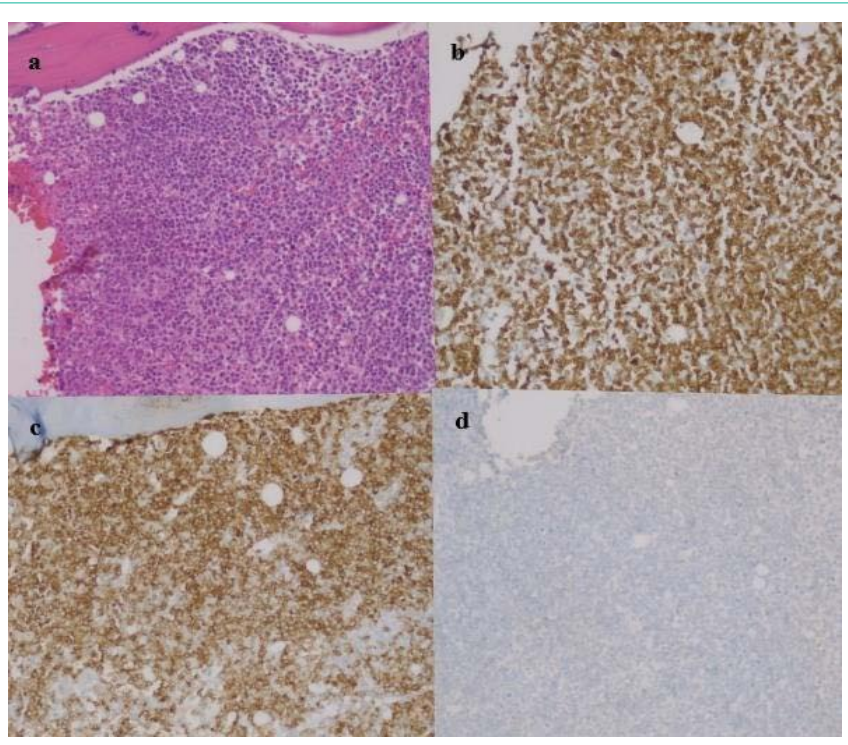

Figure 1: Histology of bone marrow biopsy. (A) hematoxylin eosin staining, $90 \%$ narrow basophilic cytoplasm blast population. (B) and (C) Immunohistochemical examinations revealed extensive and strong positive with CD3 and CD10. (D) Tumour cells were negative for TdT stain.

was given. The chemotherapy schedule explained in Table 1.

After the second cycle, she went into remission and no CSF findings were found in favor of central involvement. Allogeneic Stem Cell Transplant (ASCT) was planned and she was a candidate for matched-unrelated donor transplantation. However, the patient died as a result of carbapenem resistant Klebsiella Pneumonia septicemia in the middle of fourth course of Augmented Hyper-CVAD therapy.

\section{Discussion}

TdT expression is a major immunophenotypic marker used to distinguish ALL cases from acute myeloid leukemia (AML). It is also useful in distinguishing B cell lymphoblastic lymphoma (TdT positive) and Burkitt lymphoma (TdT negative). Almost all of ALL cases express TdT [17]. First, in 1999, Faber et al. reported three cases with TdT negative T-ALL [18].

According to the prospective study of UKALL XII / ECOG 2993 in T-ALL; having a leukocyte count >100x109/L, complex karyotype ( $\geq 5$ chromosomal anomaly), central nervous system involvement

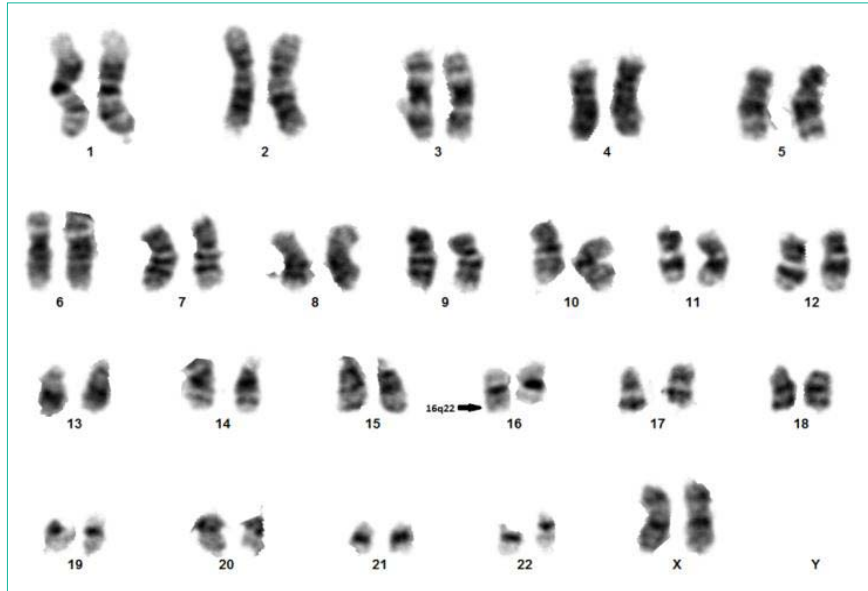

Figure 2: Cytogenetic analysis shows del (16) (q22).

were accepted as risk factors for poor prognosis [8]. In a study by Zhou et al. TdT negativity was accepted as an independent risk factor for poor prognosis in T-ALL patients [16]. ETP-positive ALL was seen in $15 \%$ of pediatric cases and was accepted in a very high-risk group [11]. TdT negative cases are more likely to accompany the ETP immunophenotype compared to TdT positive cases [16].

More than $50 \%$ of T-ALL patients have NOTCH1 mutation and 10-15\% have FBXW7 mutation. The presence of these mutations is considered among the risk factors for poor prognosis [19-21]. However, isolated del (16) (q22) was detected in the karyotype analysis in our case. Isolated del (16q) in studies and case series; Refractory Anaemia with Excess Blasts (RAEB) has been reported in patients with chronic myelomonocytic leukemia and AML, but its prognostic significance has not been established [22-25].

Among T-ALL, there are many first-line treatment options such as Augmented Berlin-Frankfurt-Munster (BFM), Hyper-CVAD, PEGasparaginase, Augmented Hyper-CVAD, methotrexate-containing combinations, hyper-CVAD and nelarabine combination [26].

Patients with TdT-negative T-ALL have a higher rate of disease progression and experience shorter overall survival. TdT-negative T-ALL is associated with a higher percentage of ETP-ALL than nonETP-ALL (42.9\% vs 12.0\%). Both ETP-ALL and TdT-negative ALL are poor independent prognostic factors and are highly correlated [27].

Table 1: Augmented HYPER-CVAD protocol schedule.

Hyper-CVAD (courses 1, 3, 5, and 7) alternated with high-dose methotrexate/ara-C (courses 2, 4, 6, and 8) administered on day 21; Hyper-CVAD = Cyclophosphamide, Vincristine, Doxorubicin, Dexamethasone + Pegaspargase

\begin{tabular}{|l|l|}
\hline Cyclophosphamide & $300 \mathrm{mg} / \mathrm{m}^{2}$ by IV over 3 hours every 12 hours for 6 doses days $1,2,3$ of \\
\hline Vincristine & $2 \mathrm{mg}$ by IV weekly for 3: Days $1,8,15$ \\
\hline Doxorubicin & $50 \mathrm{mg} / \mathrm{m}^{2}$ by IV over 24 hours \\
\hline Dexamethasone & $80 \mathrm{mg} \mathrm{by} \mathrm{IV} \mathrm{daily} \mathrm{days} 1-4$ and $15-18$ \\
\hline G-CSF & $10 \mathrm{mcg} / \mathrm{kg} /$ day by IV or subcutaneously within $72 \pm 48$ hours \\
\hline Methotrexate & $200 \mathrm{mg} / \mathrm{m}^{2}$ by IV over 2 hours followed by $800 \mathrm{mg} / \mathrm{m}^{2}$ over 22 hours on day 1 \\
\hline Ara-C & $3 \mathrm{gm} / \mathrm{m}^{2}$ by IV every 12 hours for 4 doses on days 2 and 3 \\
\hline Pegaspargase & 2000 units $/ \mathrm{m}^{2}$ by IV on day 5 of even courses \\
\hline This regimen includes CNS prophylaxis with systemic therapy(methotrexate and ARA-C) \\
\hline
\end{tabular}


Inv (16) causes a fusion transcript by rearrangement of the CBFB gene located at 16q22 and the MYH11 gene located at 16p13.1. The product of the CBFB-MYH11 gene fusion blocks embryonic hematopoiesis at the stem-progenitor cell level and impairs neutrophilic differentiation [28]. The E-cadherin gene (E-cad) on chromosome 16q22.1 encodes a protein product important in the maintenance of the epithelial phenotype mediated by a Ca++dependent, homotypic cell-cell adhesion. The gene has been termed a "metastasis suppressor" gene, because the E-cadherin protein can suppress tumor cell invasion and metastasis [29]. There are many studies on the association of $16 \mathrm{q} 22$ deletions with myeloid neoplasms and carcinomas [30]. Its relation to lymphoid neoplasms is not clear.

We considered it appropriate to give Augmented Hyper-CVAD protocol because our patient was in the Young Adult and Adolescent (AYA) ALL group and we predicted poor prognosis.

\section{Conclusion}

Our patient also had both TdT negative and ETP immunophenotype. Therefore, we predicted that it would have a poor prognosis. Based on the literature data, we thought that stem cell transplantation was the most appropriate option after the first remission in these patients due to its poor prognosis. Since it is not seen frequently and there are not enough cases in the literature, the available data is limited and more cases are needed. Prognosis may improve with increasing treatment options over time.

\section{References}

1. National Cancer Institute. SEER Cancer Statistics Review, 1975-2015 leukemia, annual incidence rates (acute lymphocytic leukemia). 2018.

2. Siegel RL, Miller KD, Jemal A. Cancer statistics, 2019. CA Cancer J Clin. 2019; 69: 7-34

3. Esparza SD, Sakamoto KM. Topics in pediatric leukemia-acute lymphoblastic leukemia. Med Gen Med. 2005; 7: 23.

4. National Cancer Institute. SEER Cancer Statistics Review, 1975-2015: overview, median age at diagnosis. 2018.

5. National Cancer Institute. SEER Cancer Statistics Review, 1975-2015: overview, age distribution of incidence cases by site. 2018.

6. Liu GJ, Cimmino L, Jude JG. Pax5 loss imposes a reversible differentiation block in B-progenitor acute lymphoblastic leukemia. Genes Dev. 2014; 28 : 1337-1350.

7. Schwickert TA, Tagoh H, Gultekin S, Dakic A, Axelsson E, Minnich M, et al Stage-specific control of early B cell development by the transcription factor Ikaros. Nat Immunol. 2014; 15: 283-293.

8. Marks DI, Paietta EM, Moorman AV, Richards SM, Buck G, DeWald $\mathrm{G}$, et al. T-cell acute lymphoblastic leukemia in adults: clinical features, immunophenotype, cytogenetics, and outcome from the large randomized prospective trial (UKALL XII/ECOG 2993). Blood. 2009; 114: 5136-5145.

9. Borowitz MJ, Chan JKC. T-lymphoblastic leukaemia/lymphoma. Editors. In: Swerdlow SH, Campo E, Harris NL, et al. WHO Classification of Tumours of Haematopoietic and Lymphoid Tissues: World Health Organization Classification of Tumours. Lyon, France: International Agency for Research on Cancer (IARC). 2008: 176-178.

10. Bene MC, Castoldi G, Knapp W. Proposals for the immunological classification of acute leukemias. European Group for the Immunological Characterization of Leukemias (EGIL). Leukemia. 1995; 9: 1783-1786.

11. Coustan-Smith E, Mullighan CG, Onciu M, Behm FG, Raimondi SC, Pei D, et al. Early T-cell precursor leukaemia: a subtype of very high-risk acute Lymphoblastic leukaemia. Lancet Oncol. 2009; 10: 147-156.
12. Kaleem Z, Crawford E, Pathan MH, Jasper L, Covinsky MA, Johnson LR, et al. Flow Cytometric analysis of acute leukemias. Diagnostic utility and critical analysis of data. Arch Pathol Lab Med. 2003; 127: 42-48.

13. Roshal M, Fromm JR, Winter S, et al. Immaturity associated antigens are lost during induction for $\mathrm{T}$ cell lymphoblastic leukemia: implications for minimal residual disease detection. Cytometry B Clin Cytom. 2010; 78: 139-146.

14. Drexler HG, Menon M, Minowada J. Incidence of TdT positivity in cases of leukemia and lymphoma. Acta Haematol. 1986; 75: 12-17.

15. Patel JL, Smith LM, Anderson J, Abromowitch M, Campana D, Jacobsen J, et al. The immunophenotype of T-lymphoblastic lymphoma in children and adolescents: a Children's Oncology Group report. Br J Haematol. 2012; 159: 454-461.

16. Zhou $Y$, Fan X, Routbort $M$, Yin CC, Singh R, Bueso-Ramos $C$, et al. Absence of terminal deoxynucleotidyl transferase expression identifies a subset of high-risk adult T-lymphoblastic leukemia/lymphoma. Modern Pathology. 2013; 26, 1338-1345.

17. Yasmeen S, Rajkumar A, Grossman H, Szallasi A. Terminal Deoxynucleotidyl Transferase (TdT)-negative Lymphoblastic Leukemia in Pediatric Patients: Incidence and Clinical Significance. Pediatric and Developmental Pathology. 2017; 20: 463-468.

18. Faber J, Kantarjian H, Roberts MW, Keating M, Freireich E, Albitar M. Terminal deoxynucleotidyl transferase-negative acute lymphoblastic leukemia. Arch Pathol Lab Med. 2000; 124: 92-97.

19. Hernandez Tejada FN, Galvez Silva JR, Zweidler-McKay PA. The challenge of targeting notch in hematologic malignancies. Front Pediatr. 2014; 2: 54.

20. O'Neil J, Grim J, Strack P, Rao S, Tibbitts D, Winter C, et al. FBW7 mutations in leukemic cells mediate NOTCH pathway activation and resistance to gamma-secretase inhibitors. J Exp Med. 2007; 204: 1813-1824.

21. Weng AP, Ferrando AA, Lee W, Morris JP, Silverman LB, Sanchez-Irizarry $\mathrm{C}$, et al. Activating mutations of NOTCH1 in human T cell acute lymphoblastic leukemia. Science. 2004; 306: 269-271.

22. Estey E, Trujillo JM, Cork A, O'Brien S, Beran M, Kantarjan H, et al. AMLassociated cytogenetic abnormalities (inv (16), del (16), $t(8 ; 21)$ ) in patients with myelodysplastic syndromes. Hematol Pathol. 1992; 6: 43-48.

23. Schiffer CA, Lee EJ, Tomiyasu T, Wiernik PH, Testa JR. Prognostic impact of cytogenetic abnormalities in patients with de novo acute nonlymphocytic leukemia. Blood. 1989; 73: 263-270.

24. Kalwinsky DK, Raimondi SC, Schell MJ, Mirro J, Santana VM, Behm F, et al. Prognostic importance of cytogenetic subgroups in de novo pediatric acute nonlymphocytic leukemia. J Clin Oncol. 1990; 8: 75-83.

25. Betts DR, Rohatiner AZ, Evans ML, Rassam SM, Lister TA, Gibbons B Abnormalities of chromosome $16 q$ in myeloid malignancy: 14 new cases and a review of the literature. Leukemia. 1992; 6: 1250-1256.

26. Jain $\mathrm{P}$, Kantarjian $\mathrm{H}$, Ravandi $\mathrm{F}$, Thomas $\mathrm{D}$, O'Brien $\mathrm{S}$, Kadia $\mathrm{T}$, et al. The combination of hyper-CVAD plus nelarabine as frontline therapy in adult T-cell acute lymphoblastic leukemia and T-lymphoblastic lymphoma: MD Anderson Cancer Center experience. Leukemia. 2014; 28: 973-975.

27. Kidoguchi K, Yokoo M, Umino A, Aoki S, Kimura S. Terminal Deoxynucleotidy Transferase (TdT) negative early $\mathrm{T}$ cell precursor acute lymphoblastic leukemia (ETP-ALL) with spontaneous acute kidney injury. Ann Hematol. 2020; 99: 885-886

28. Rogers HJ, His ED, Tang G, Wang SA, Bueso-Ramos CE, Lubin D, et al. Most Myeloid Neoplasms with Deletion of Chromosome 16q are Distinct from Acute Myeloid Leukemia with Inv (16) (p13.1q22): A Bone Marrow Pathology Group Multicenter Study, American Journal of Clinical Pathology. 2017; 147: 411-419.

29. Paul R, Ewing C, Jarrard D, Isaacs W. The cadherin cell-cell adhesion pathway in prostate cancer progression. British Journal of Urology. 1997; 79 37-43.

30. Melki JR, Vincent PC, Brown RD, Clark SJ. Hypermethylation of E-cadherin in leukemia Blood. 2000; 95: 3208-3213. 